\title{
Heterotopias urbanas: Espaços de poder e estratégias sócio-espaciais dos Sem-Teto no Rio de Janeiro*
}

\author{
Tatiana Tramontani Ramos \\ Universidade Federal do Rio de Janeiro. Rio de Janeiro, Brasil. Email: \\ tatiana_tramontani@yahoo.com
}

\begin{abstract}
Resumo: O artigo é uma tentativa de aproximação entre das lutas travadas pelo movimento dos sem-teto no Rio de Janeiro e a idéia de heterotopia assim como foi elaborada e (pouco) desenvolvida por Michel Foucault. As estratégias desse movimento, suas formas de reapropriação e resignifiação dos espaços urbanos, poderiam ser identificadas, nesse quadro teórico, como contribuições para a criação e manutenção de enclaves insurgentes na cidade, isto é, heterotopias urbanas. Estes seriam espaços criados, definidos, reproduzidos a partir de relações de poder situadas. Ao contrário das utopias que seriam espaços imateriais, ilusórios, idealizados, possivelmente inalcançáveis, as heterotopias seriam espaços concretos e reais, utopias efetivamente realizadas. Incorporar a análise das heterotopias foucaultianas, à compreensão da dinâmica socioespacial das ocupações dos semteto pode ser importante, pois estas são práticas que residem e se equilibram justamente entre, de um lado o "formal”, o "institucional”, o "moralmente aceito" e, do outro, aquilo que é necessário, justo, viável, possível, para a sobrevivência na cidade. As heterotopias seriam essas formas de resignificação e reapropriação que garantem a sobrevivência daqueles que vivenciam o espaço, com todas as suas contradições e conflitos de interesses.
\end{abstract}

Palavras-chave: Espaço, urbano, poder, conflito, movimentos sociais

\section{Heterotopías Urbanas: Espacios de poder y estrategias socio-espaciales de los sin techo en Río de Janeiro}

Resumen: El artículo es un intento de acercamiento entre las luchas de los movimientos de las personas sin hogar en Río de Janeiro y la idea de heterotopía, tal como fue elaborada y (poco) desarrollada por Michel Foucault. Las estrategias de este movimiento, y sus formas de resignificación y reapropiación de los espacios urbanos pueden identificarse con ese marco teórico, como contribuciones a la creación y mantenimiento de enclaves insurgentes en la ciudad, esto es, heterotopías urbanas. Éstos serían espacios creados, definidos, reproducidos a partir de relaciones de poder localizadas. A diferencia de las utopias que serían espacios inmateriales, ilusorios, idealizados y posiblemente inalcanzables, las heterotopías serían espacios concretos y reales, utopias efectivamente realizadas. Incorporar el análisis de las heterotopías de Foucault en la comprensión de las dinámicas socioespaciales de ocupaciones de los sin techo puede ser importante, porque se trata de prácticas que residen y están equilibradas con precisión entre, por un lado, lo “formal”, lo “institucional”, lo “moralmente aceptado” y, por el otro, lo que es necesario, justo, factible, posible, para sobrevivir en la ciudad. Las heterotopías serían esas formas de resignificación y reapropiación que garantizan la supervivencia de las personas 
que vivencian el espacio, con todas sus contradicciones y conflictos de intereses. Palabras clave: espacio, poder urbano, conflictos, movimientos sociales

\title{
Urban heterotopias: Empowered spaces and socio-spatial strategies of homeless movement in Rio de Janeiro
}

\begin{abstract}
The article is an attempt to approche the struggles waged by the homeless movement in Rio de Janeiro and the idea of heterotopia as it was developed by Michel Foucault. The strategies of this movement, its forms of re-appropriation and re-signification of urban spaces, could be identified in this framework as contributions to the creation and maintenance of insurgent enclaves in the city, i.e. urban heterotopias. These spaces would be created, defined and reproduced from emplaced power relations. Unlike the utopia, that would be immaterial, illusory, idealized, possibly unattainable spaces, heterotopias would be concrete and real spaces, actually performed utopias. The incorporation of the analysis of foucauldian heterotopias, to understanding the socio-spatial dynamics of the homeless may be important, because these are practices which reside, and are precisely balanced, between, on one hand, the "formal", the "institutional", the "morally accepted", and on the other, with what is necessary, fair and possible for survival in the city. The heterotopias would be such forms of reframing and re-appropriation to ensure the survival of those who experience the space, with all its contradictions and conflicts of interest.
\end{abstract}

Key-words: Space, urban, power, conflict, social movements.

$* * *$

\section{A idéia de heterotopia}

Antes da discussão e do desenvolvimento da própria idéia heterotopia, tema que motivou o texto "Espaços Outros"1 de Michel Foucault, logo nos primeiros parágrafos, o autor contribui para a elaboração - talvez não intencionalmente - do método ou estratégia de elaboração teórica que, em outras obras e em outros momentos de sua reflexão sobre o poder, ele vai denominar genealogia.

Nos interessa esse tipo de análise foucaultiana para os fatos e fenômenos sócio-espaciais que aqui serão apresentados, pois tal proposta de reflexão independe do marxismo, bem como da dialética, da fenomenologia e da semiótica como formas de refletir sobre o sujeito (e suas ações) na história, para privilegiar uma leitura dos acontecimentos a partir das próprias lutas sociais, das estratégias e táticas que compõem essas lutas. Isto é, dos limites e possibilidades engendrados nas próprias lutas urbanas através do alcance dos ganhos calculados, planejados e obtidos. Da definição de como esses recursos serão alocados, a curto, médio e longo prazo.

Ou ainda, em outras palavras, o artigo de Michel Foucault sobre as heterotopias, ainda que cronologicamente anterior aos outros trabalhos onde 
o conceito de genealogia em Foucault será desenvolvido com maior fôlego e profundidade, já dá pistas para que seja possível enxergar nele um esboço de uma "genealogia" enquanto esforço metodológico na análise do poder, mas também, do espaço. Em nosso caso, do espaço urbano. Das lutas que contribuem para a gênese desse espaço urbano.

Arriscamos tal afirmação, pois, de certa maneira, Foucault, em "Outros Espaços", vai tentar ultrapassa o que ele vai chamar de "teorias totalitárias globais", em favor das "críticas descontínuas, particulares e locais”. Isto é, parte de uma concepção do espaço que está reduzida ao "espaço de localização", uma hierarquia entre lugares característica da Idade Média, para o "espaço da extensão", aquele desvelado por Galileu no século XVII, até chegar ao que este autor vai denominar de "espaço do posicionamento", onde as relações de vizinhança de proximidade e distância ganham maior destaque. Neste percurso, Foucault desvenda, não para a Geografia, mas para sua própria teoria e obra, o espaço relacional e aponta para uma "produção teórica" ao menos potencialmente, mais autônoma, não centralizada e que dispensa a concordância de um sistema comum que a valide.

Refletindo de forma mais direta, ousamos pensar que, o "despertar”, neste texto, para o espaço em seu sentido relacional (algo que não era, em 1984, uma "novidade” na Geografia), um espaço que se define a partir das relações entre posicionamentos absolutamente irredutíveis uns aos outros e capazes de produzir diferentes configurações, de reafirmar a sua qualidade de espaço relacional, qualificando-o ainda como um espaço heterogêneo, enriquece ainda mais as contribuições de Michel Foucault para as ciências sociais, de modo geral, e também para a Geografia. Como o autor afirma,

seria preciso fazer uma "história dos espaços" - que seria ao mesmo tempo uma "história dos poderes" - que estudasse desde as grandes estratégias da geopolítica até as pequenas táticas do habitat, da arquitetura institucional, da sala de aula ou da organização hospitalar, passando pelas implantações econômico-políticas. É surpreendente ver como o problema dos espaços levou tanto tempo para aparecer como problema histórico-político: ou o espaço era remetido à "natureza" - ao dado, às determinações primeiras, à "geografia física”, ou seja, a um tipo de camada pré-histórica, ou era concebido como local de resistência ou de expansão de um povo, de uma cultura, de uma língua ou de um Estado. Em suma, analisava-se o espaço como solo ou como ar; o que importava era o substrato ou as fronteiras. Foi preciso Marc Bloch e Fernand Braudel para que se desenvolvesse uma história dos espaços rurais ou dos espaços marítimos. É preciso dar continuidade à ela e não ficar somente dizendo que o espaço pré-determina uma história que por sua vez o modifica e que se sedimenta nele. A fixação espacial é uma forma econômicopolítica que deve ser detalhadamente estudada. (Foucault, 1998:212, grifos e aspas do autor) 
Apesar dos meandros percorridos pela discussão acerca do espaço no texto “Outros Espaços”, Foucault deixa claro que seu interesse não está em uma análise profunda sobre o conceito de espaço e sua multiplicidade e heterogeneidade, nem na análise de determinados padrões ou regularidades que o compõe. Ao que tudo indica, seu interesse está na análise de "determinados posicionamentos que carregam em si a propriedade de estar em relação com todos os outros posicionamentos, mas de tal modo que suspendem, neutralizam ou invertem o conjunto de relações por eles designadas” (Foucault, 2001:414). Em outras palavras, eles estão conectados a todos os outros, porém definem-se a partir de suas próprias posições, ou até mesmo, a partir de "contra-posições”. Esses espaços seriam as heterotopias. Espaços criados, definidos, reproduzidos a partir de relações de poder situadas. Ao contrário das utopias que seriam espaços imateriais, ilusórios, idealizados, possivelmente inalcançáveis, as heterotopias seriam espaços concretos e reais, utopias efetivamente realizadas. Seriam lugares que estão fora de todos os lugares, mas ainda assim, localizáveis. Absolutamente diferentes de tudo aquilo que parecem refletir.

\section{As heterotopias urbanas: espaços de poder e luta}

O nosso interesse em analisar, ou melhor, aproveitar as análises de Foucault a respeito das heterotopias está, justamente, em buscar uma compreensão um pouco mais aprofundada das lutas espaciais travadas pelos movimentos sociais urbanos, mais especificamente o movimento dos sem-teto no Rio de Janeiro, na medida em que possamos (ou não) comparar, ou aproximar as estratégias e táticas desse movimento, através da reapropriação e resignifiação dos espaços uranos. Tais estratégias e táticas de luta poderiam ser identificadas, nesse quadro teórico, como contribuições para a criação e manutenção de enclaves insurgentes no sentido da luta pela moradia e pelo direito ao trabalho e sobrevivência, em outros termos, heterotopias urbanas.

Essa aproximação surge da especulação acerca do fato de que Foucault, ao longo de quase toda a sua produção, majoritariamente privilegiou a dimensão de análise do poder que controla e disciplina a sociedade e os indivíduos. Seja esse um poder "maiúsculo", transcendente, os macro-poderes como (mas não exclusivamente) os aparelhos de Estado, sejam os micro-poderes, aqueles imanentes às relações sociais, que se exercem ao nível de sua "microfísica”. Mas sempre se tratando do poder que contribui para a heteronomia, isto é, para a alienação das decisões próprias em favor de outrem. Como bem referencia Souza (2006):

Infelizmente, no caso de Foucault, assim como no caso da maioria dos marxistas, o interesse por uma crítica social que leve em conta, fortemente, a dimensão espacial da sociedade se deu muito mais em função de uma análise e uma denúncia de relações sociais e espacialidades heterônomas do que para investigar relações sociais e espacialidades autônomas ou, pelo menos, propiciadoras de substanciais 
ganhos de autonomia. (Souza, 2006:316)

Ao aprofundar suas discussões acerca da "genealogia do poder" através de uma "arqueologia do saber”, Foucault contribui de forma inestimável para a novas formas de abordagem da discursividade local, para a ativação de saberes "libertos da sujeição" (sujeição moral, capital etc.), o que contribui para a ampliação do leque de possibilidades e perspectivas de análise do poder na sociedade ${ }^{2}$.

Esses tipos de abordagem do poder não buscam a sua origem, nem os seus mecanismos gerais, mas as suas ramificações e capilaridades. Não indaga nem pretende responder "quem detém o poder", mas qual a sua intenção, onde ele se relaciona com seu objeto, seu alvo, onde ele produz seus efeitos. Não toma o poder como algo que possa ser dividido, concentrado ou apropriado como um bem, uma riqueza, mas sim como algo que circula, funciona em cadeia, em rede e, a partir desse tipo de funcionamento, contribui para as diferentes formas de uso e apropriação dos espaços. Desta forma, o poder, em Foucault, assim como em Arendt (2003), não se aplica aos indivíduos como alvos inertes, mas é transmitido através deles e depende deles para existir.

Quando penso na mecânica do poder, penso em sua forma capilar de existir, no ponto em que o poder encontra o nível dos indivíduos, atinge seus corpos, vem se inserir em seu gestos, sua atitudes, seus discursos, sua aprendizagem, sua vida quotidiana. (Foucault, 1998:131)

A teoria do Estado, a análise tradicional dos aparelhos de Estado sem dúvida não esgotam o campo de exercício e de funcionamento do poder. Existe atualmente um grande desconhecido: Quem exerce o poder? Onde o exerce? Atualmente se sabe, mais ou menos, quem explora, para onde vai o lucro, por que mãos ele passa e onde ele se reinveste, mas o poder... Sabe-se muito bem que não são os governantes que o detêm. (...) Além disso, seria necessário saber até onde se exerce o poder, através de que revezamentos e até que instâncias, freqüentemente ínfimas, de controle, de vigilância, de proibições, de coerções. Onde há poder ele se exerce. Ninguém é, propriamente falando, seu titular; e, no entanto, ele sempre se exerce em determinada direção, com uns de um lado e outros do outro; não se sabe ao certo quem o detém, mas se sabe quem não o possui. (Foucault, 1998: 75)

Quando fala da disciplina e do controle, Foucault fala da criação de aparelhos de poder/saber e de múltiplos domínios de conhecimento, com um discurso alheio ao da "lei” e da "regra”. Sua regra não é a regra jurídica, mas a regra "natural”, a norma, a normatização que é, para ele, domínio das ciências humanas, não jurídicas.

Controle: não se trata de cuidar do corpo, em massa, grosso modo, como se fosse uma unidade indissociável mas de trabalhá-lo 
detalhadamente; de exercer sobre ele uma coerção sem folga, de mantê-lo ao nível mesmo da mecânica - movimentos, gestos, atitude, rapidez: poder infinitesimal sobre o corpo ativo.(...) Esses métodos que permitem o controle minucioso das operações do corpo, que realizam a sujeição constante de suas forças e lhes impõem uma relação de docilidade-utilidade, são o que podemos chamar as “disciplinas” (Foucault, 1998a: 118, grifos e aspas do autor.).

Mesmo que essa discussão sobre o poder não seja, diretamente uma discussão espacial, a dimensão do espaço, a organização espacial dos corpos a disciplinarização no espaço, são elementos fundamentais nesse tipo de análise. Foucault faz questão de ressaltar que, no efeito do poder sobre os corpos, não se trata de confundir ou igualar o poder à repressão, pois

se o poder tivesse apenas a função de reprimir, se agisse apenas por meio da censura, da exclusão, do impedimento, do recalcamento, à maneira de um grande super-ego, se apenas se exercesse de um modo negativo, ele seria muito frágil. Se ele é forte, é porque produz efeitos positivos a nível do desejo - como se começa a conhecer - e também a nível do saber (sic). O poder, longe de impedir o saber, o produz. (Foucault, 1998: 148)

Aliás, outras distinções neste sentido foram feitas de forma lapidar por Hannah Arendt em seu texto Da Violência, de 1958. Para esta autora, o poder "corresponde à habilidade humana de não apenas agir, mas agir em uníssono, em comum acordo”, jamais sendo propriedade de um indivíduo, mas pertencente a um grupo e enquanto o grupo estiver e se mantiver unido. É esta “união”, essa coesão que garante, segundo a autora, a legitimidade do poder. O poder só existe quando possui respaldo, legitimidade. Por isso, Hannah Arendt faz questão de ressaltar a distinção entre poder e outros instrumentos como a força, vigor, autoridade e violência.

Talvez não seja supérfluo acrescentar que essas distinções, embora não sejam de modo algum arbitrárias, dificilmente correspondem ao mundo real, de onde são, entretanto, retiradas. Assim o poder institucionalizado nas comunidades organizadas aparece freqüentemente sob a feição de autoridade, a exigir imediato reconhecimento; sociedade alguma poderia funcionar sem ela. (...) Ademais, nada, conforme vemos, é mais comum que a combinação da violência com o poder, nada menos freqüente do que encontrálos em sua forma mais pura e, portanto, mais extrema. Não se pode concluir daí que a autoridade, o poder e a violência sejam a mesma coisa. (Arendt, 2003:29)

Eis o nosso interesse. Quando este “poder” parece se mostrar de formas diversificadas, capazes de desviar do "senso comum”, da noção de poder que remete àquilo que é ou faz “mal”, sinônimo de repressão e a coação, e passa a ser analisado sob as suas mais diferentes formas, na organização de espaços e definição de territórios, nos diversos usos possíveis 
desse espaço, nas contra-definições, nos espaços definidos por aquilo que eles não são (pela ausência, pela carência, pela sanção) - "ausência do Estado”, “ausência do Poder Público”, “ausência de Planejamento e de projetos”, “carência de infra-estrutura, de habitação, de trabalho” - nos desvios da norma, este poder se torna o poder imanente, legitimado justamente por sua "mundanidade" (Arendt, 2003). O poder que está nas ruas, no cotidiano, que se faz no fazer das pessoas. Esse poder imanente, cotidiano, “microbiano” será, também, objeto de análise de Michel de Certau. O poder que constitui as

práticas microbianas, singulares e plurais, (...) procedimentos que, muito longe de ser controlados ou eliminados pela administração panóptica, se reforçam em uma proliferação legitimada, desenvolvidos e insinuados nas redes de vigilância, combinados segundo táticas ilegíveis mas estáveis a tal ponto que constituem regulações cotidianas e criatividades sub-reptícias que se ocultam somente e graças aos dispositivos e aos discursos, hoje atravancados, da organização observadora. Esse caminho poderia inscrever-se como uma seqüência, mas também como a recíproca da análise que Michel Foucault fez das estruturas de poder. (...) Mas a esses aparelhos produtores de um espaço disciplinar, que práticas do espaço correspondem, do lado onde se joga (com) a disciplina? $\mathrm{Na}$ conjuntura presente de uma contradição entre o modo coletivo da gestão e o modo individual de uma reapropriação, nem por isso essa pergunta deixa de ser essencial, caso se admita que as práticas do espaço tecem, com efeito, as condições determinantes da vida social. (De Certau, 1996: 175)

São esses espaços das práticas microbianas, da microfísica do poder, o poder sub-reptício, fruto das práticas socioespaciais mais cotidianas, mais comuns, mas, ao mesmo tempo, dotadas de elementos que fundamentam, a existência de "espaços outros” no que se refere a outros tipos de relações de poder espacializadas e outra dimensão do poder nas relações sociais, o que poderíamos chamar, de acordo com Foucault, de "heterotopias".

Espaços onde as relações de poder podem ser lidas através de práticas que se equilibram entre a gestão institucional (o que formalmente se espera, o que é “permitido”, o que se “aprova”, o poder formal) e aquilo que é (re)apropriado, (re)significado, contrariado, subvertido a partir das práticas cotidianas dos que verdadeiramente “usam”, produzem, se reproduzem no espaço. Práticas essas que permanentemente atualizam forças, lutas, embates e contradições entre diferentes interesses e significados.

Daí a importância, ao nosso ver, de incorporar a análise das heterotopias produzidas por Foucault, à compreensão da dinâmica socioespacial do movimento dos sem-teto, pois são práticas que residem e se equilibram justamente entre, de um lado o "formal”, o "institucional”, o “moralmente aceito” e, do outro, aquilo que é necessário, justo, viável, 
possível, para a sobrevivência na cidade, nas lutas cotidianas. As heterotopias serão justamente essas formas de resignificação e reapropriação que garantem a sobrevivência e a reprodução daqueles que produzem e usam o espaço, com todas as suas contradições e conflitos de interesses.

Entender as heterotopias, bem como entender o poder em Foucault, é uma tarefa que exige a análise das suas ramificações, de sua atomização, e não a busca de sua origem, seus mecanismos gerais, seus objetivos últimos. Exige que se analise onde e como essas relações se desenrolam, onde seus efeitos são produzidos, que mecanismos elas engendram e que contraposições imprimem.

As heterotopias, segundo Foucault, estão presentes em toda e qualquer cultura, por isso, não possuem uma "forma padrão" um "tipo universal”. Ao contrário, são diametralmente opostas às "formas totalizadoras” que homogeneízam, ou à unicidade e transcendência que remetem ao que ele vai nomear "espaço sacralizado”, não (apenas) a sacralização religiosa, mas aquela que diz respeito aos dispositivos institucionais e da práxis social:

Ora, apesar de todas as técnicas nele investidas, apesar de toda a rede de saber que permite determiná-lo ou formalizá-lo, o espaço contemporâneo talvez não esteja ainda inteiramente dessacralizado (...). Houve, certamente, uma certa dessacralização teórica do espaço (aquele que a obra de Galileu provocou), mas talvez não tenhamos ainda chegado à uma dessacralização prática do espaço. E talvez nossa vida ainda seja comandada por um certo número de oposições nas quais não se pode tocar, as quais a instituição e a prática ainda não ousaram atacar: oposições que admitimos como inteiramente dadas: por exemplo, entre o espaço privado e o espaço público, entre o espaço da família e o espaço social, entre o espaço cultural e o espaço útil, entre o espaço de lazer e o espaço de trabalho; todos são ainda movidos por uma secreta sacralização. (Foucault, 2001: 413)

Fugindo às "formas totalizadoras e sacralizadas", as heterotopias remeteriam a formas de organização mais autônomas, não-centralizadas e que não têm necessidade, para serem válidas, da concordância de um sistema comum, o que não quer dizer um ecletismo débil, práticas oportunistas, total permeabilidade a qualquer proposta ou empreendimento, ou, um ascetismo plenamente voluntário. O fato de, muitas vezes, irem na contramão desse "sistema", não significa pobreza política e "princípio do sercontra”, mas saberes (e poderes) particulares, locais, regionais, diferenciados, não-unânimes, politicamente divergentes e que, por isso, devem sua força somente à dimensão que os opõe à todos aqueles que o circundam. Trata-se de uma insurreição dos saberes ("de baixo") contra os efeitos de poder centralizadores e centralizados (“de cima”).

Assim, as heterotopias, em sua "forma multiplicidade", em sua imanência (em sua "não-titularidade”) e não em sua transcendência 
(governantes, dirigentes, burocratas e gestores), conseguem transpor ou "driblar", de certa forma, a instituição. Inscrevem o poder no espaço e escapam à norma e à regra geral, ao que se espera.

Contudo, para Foucault, neste processo de transposição, as heterotopias podem tornar-se críticas (heterotopia da crise), rompendo com o status quo, com a norma geral, com as instituições socialmente aceitas e criando comportamentos e espaços onde o que predomina é o rompimento (a crise). Podem ainda tornar-se desviantes (heterotopia do desvio) no caso de um comportamento que fuja aos padrões, mas, ainda assim, seja encontrado na sociedade, em espaços determinados que dão origem a espaços/ territórios desviantes. Podem fazer funcionar de maneira diferente formas e organizações espaciais que sempre existiram, criando "espaços outros", como é o caso dos cemitérios e sua presença ao longo da história das civilizações humanas, exemplo mencionado pelo autor no texto (Foucault, 2001). Enfim, as heterotopias podem reunir, ao mesmo tempo e em uma mesma posição, a menor parcela do mundo e também todo o mundo em justaposição, com usos e significações múltiplas do mesmo espaço, como é o caso dos jardins e parques e outros espaços de acesso público.

\section{Estratégia sócio-espacial dos sem-teto: "Espaços Outros”}

Se tomarmos como ilustração a experiência do movimento dos semteto em atuação desde 1997 em São Paulo e, mais recentemente no Rio de Janeiro, veremos que as ações postas em prática por esses sujeitos contribuem para a criação de heterotopias no espaço urbano dessas duas grandes metrópoles brasileiras na medida em que questionam, subvertem, transgridem a ordem institucional pré-estabelecida.

São movimentos críticos, pois rompem com o status quo, com a norma geral que rege a vida urbana formal e institucional, criando e transformando espaços ao promoverem as ocupações de edificações e terrenos. Rompem não só no sentido de transgredir a lei de propriedade (pública ou privada), de apropriar-se do bem (imóvel) "alheio", mas no sentido de desequilibrar a ordem vigente, a ordem heterônoma, imposta, não participativa e, por tudo isso, não democrática. Rompem com o status quo, não só por normas e usos diferenciados do espaço urbano, mas por ousar questionar a "ordem capitalista" das coisas: o que se tem é o que se compra, o que se herda do trabalho de outros, o que se "constrói e conquista a partir de mérito individual”. A "nova ordem” colocada pelas ocupações de sem-teto nos centros urbanos inverte a lógica do capital e prioriza o uso em detrimento da acumulação, a justiça social em detrimento da justiça oficial, o direito em detrimento do Direito.

Terrenos, prédios e galpões abandonados, fábricas há tempo desativadas, ruínas de antigas edificações urbanas, são transformados, resignificados, re-apropriados por pessoas que passam a dar vida a esses espaços, tornando-os, realmente, parte do espaço urbano. Isso, porque, sem 
os sujeitos que vão dar vida, vão reproduzir esses espaços, sua significação para o contexto mais amplo da cidade torna-se nula.

Por mais relevante que seja o substrato, do ângulo da mudança social é evidente que ele não tem interesse isoladamente; não importa o espaço social “morto”, mas sim o espaço "vivo”, que é “vivificado” pela sua relação com os seus produtores. E o espaço social, em suas várias facetas, por condicionar as relações sociais, é uma dimensão essencial da sociedade concreta. (Souza, 2006:111, aspas do autor.)

Porém, como nos mostrou Foucault, esses espaços de que tratamos, os espaços apropriados e re-produzidos pelos sem-teto, ainda que estejam dentro do espaço urbano carioca ou paulista, ainda que totalmente conectados aos outros espaços da cidade, integrados, "vivificados" por seus habitantes e produtores, pela necessidade de trabalho e sobrevivência, pela cultura e lazer, pelos vínculos emocionais e sentimentais, familiares e de amizade, esses espaços, ainda assim, carregam em si ou o estigma da ilegalidade, da violência e do desrespeito que os tornam "mal vistos" pela sociedade da qual fazem parte e para a qual trabalham e produzem, ou a capacidade de suspender, neutralizar e inverter o conjunto de relações por eles designadas, através de novos tipos de relações sociais: propriedade e uso coletivo dos espaços, formas alternativas e solidárias de trabalho e geração de renda.

O que era fábrica vira moradia, o que era terreno baldio vira horta e pomar, o que era estacionamento vira espaço de trabalho e produção coletiva. Em outras palavras, esses espaços estão conectados a todos os outros, visto que são edificações ou terrenos que fazem parte do substrato da cidade com suas fachadas, calçadas, que já tiveram diferentes funções, diferentes formas, foram partes de outros processos e estruturas sociais, porém, atualizam-se e atualizam o espaço da cidade não como meras rugosidades espaciais, como espaços mortos, decadentes, que precisam de "revitalização", mas como formas diferenciadas de dar nova funcionalidade, significado e sentido às formas pré-existentes.

Esses espaços outros, essas heterotopias urbanas, independentemente do julgamento e da interpretação do poder público (do Estado de direito) e da sociedade civil instituída, definem-se a partir de suas próprias posições, ou até mesmo, a partir de “contra-posições”, na medida em que questionam a propriedade privada diante do imenso déficit habitacional no país, na medida em que questionam a perseguição implacável dos órgãos de repressão públicos ao trabalhador informal (camelôs, ambulantes, prestadores de serviços etc.) diante das imensas fileiras de desempregados, subempregados hiperexplorados existente no país.

Questionam os “projetos revitalização de regiões centrais de negócios” - em muitas cidades do Brasil e do mundo, áreas urbanas obsolescentes - bem como “revitalização da Zona Portuária”, no caso do 
Rio de Janeiro, ambas propostas pelo Estado e Prefeituras, diante do (quando muito) "despejo" da população pobre em distantes bairros das periferias metropolitanas.

Questionam a validade de se manterem espaços vazios, desabitados nas áreas centrais da cidade - justamente aquelas mais bem servidas de transportes públicos, equipamentos de uso coletivo, espaços de cultura e lazer - diante da constante elevação do custo de vida como os preços dos transportes (o que dificulta os deslocamentos diários de casa para o trabalho e do trabalho para casa), dos aluguéis, os impostos diretos e indiretos, os serviços básicos como luz, água, gás e saneamento básico. Enfim, se posicionam, se colocam, definem seus espaços a partir de outros espaços, mas sem deixar de enfatizar que sua posição, e aqui entenda-se posição como situação, localização, sua geografia, como uma contra-posição, uma insurgência ao formal, moral e legalmente instituído.

As heterotopias, neste caso, representam relações sociais e de poder espacializadas, desviantes ou não, transgressoras ou não, questionam estruturas profundamente enraizadas. Contudo, apresentando-se como formas espaçais alternativas ou bastante específicas, nunca deixam de estar ligadas à recortes e períodos de tempo, à conjunturas históricas singulares e, logo, não deixam de ser, também, heterocronias.

Podem configurar sistemas com diferentes "graus" de abertura e fechamento do espaço - como os exemplos da agora e da ekklèsia ou a própria casa, o oikos, mencionados por Castoriadis:

Fazemos a distinção entre o oikos, os negócios estritamente privados; a agora, a esfera privada/pública, o "lugar" onde os cidadãos se encontram fora do domínio político; e a ekklèsia, a esfera pública/pública, isto é, em regime democrático, o lugar onde se delibera e se decide sobre os negócios comuns. Na agora, discuto com outras pessoas ou compro livros, ou qualquer outra coisa, estou em um espaço público, mas que é ao mesmo tempo privado, pois nenhuma decisão política (legislativa, governamental ou judiciária) pode ser tomada aí; a coletividade, por sua legislação, nos assegura apenas a liberdade desse espaço. Na ekklèsia no sentido amplo, compreendo tanto a "assembléia do povo" quanto o "governo" e os tribunais, estou em um espaço público/público: delibero com outras pessoas para decidir, e tais decisões são sancionadas pelo poder público da coletividade. A democracia pode ser definida também como o devir realmente público do domínio público/público - que, em outros regimes, é efetivamente mais ou menos privado. (Castoriadis, 2004:208, grifos e aspas do autor)

Esses diferentes graus de "abertura e fechamento" são trabalhados de forma muito mais enriquecedora dentro desses espaços das ocupações, vide a importância dada aos espaços de uso coletivo, aos espaços públicos por excelência, a forma como os moradores entendem e se entendem no 
espaço da cidade. Ou a forma como trabalham os espaços coletivos dentro da ocupação, a esfera privada/pública, onde questões que remetem ou atingem de certa forma o coletivo dos moradores, ou parte desse coletivo, são discutidas e participadas à todos que desejem dela compartilhar através das assembléias regulares ou reuniões extraordinárias. Até mesmo a esfera privada, o oikos, a casa, esse ambiente tão íntimo que é a moradia da família é tratado de forma diferente quando comparara a outros prédios, condomínios e até mesmo espaços de baixa renda como favelas e loteamentos irregulares. Nesses espaços outros, os espaços das ocupações a esfera privada não se define pela propriedade enquanto acumulação de riqueza, mas pelo uso e compartilhamento do espaço, necessário e fundamental à reprodução da vida de todos. Tanto que essas moradias, por decisão do coletivo, não podem ser vendidas, trocadas, alugadas ou sublocadas pelos moradores da ocupação, mesmo diante da posse definitiva do imóvel mediante vitória em ação judicial, a idéia é que o imóvel continue de propriedade, uso e manutenção coletiva, sem parcelamento em unidades habitacionais privadas. Um trabalho muito interessante sobre esse assunto é o de Almeida, Grandi e Moreira (2009).

As heterotopias possuem uma função em relação ao resto do espaço, seja no sentido de produzir ilusões de ordem ou de desordem em compensação às medidas de desordem e ordem dos espaços institucionalizados da sociedade em geral, mas sempre conduzem à idéia de que a estrutura não é monolítica e a conjuntura não é imobilizadora. Ao contrário. É justamente por meio das fissuras na estrutura e das múltiplas possibilidades e caminhos contidos na conjuntura que é possível construírem-se espaços outros. Neste caso aqui mencionados, mais dignos, mais humanos e solidários.

\section{Relações autônomas e heterônomas: formas de apropriação e controle do espaço urbano}

O cerne dessa nova/diferente interpretação e apropriação do espaço urbano está justamente na distinção entre a heteronomia e seu impacto presente em quase todos os espaços sociais, e a autonomia enquanto potência de ser e de agir individual e coletivamente. Um autor que muito se dedicou à essa teorização foi Cornelius Castoriadis e, para esse, o cerne da discussão está precisamente no entendimento do que seja o poder, suas ramificações, e suas instituições, o que Castoriadis vai definir como

a capacidade para qualquer instância que seja (pessoal ou impessoal), de levar alguém (ou vários) a fazer (ou não fazer) o que, entregue a si mesmo, ele não faria necessariamente (ou faria talvez), é imediato que o maior poder concebível é o de pré-formar alguém, de tal modo que por si mesmo ele faça o que queríamos que fizesse, sem nenhuma necessidade de dominação (Herrschaft) ou de poder explícito para levá-lo a... Da mesma forma é imediato que isso, para o sujeito 
submetido a essa formação, ao mesmo tempo corpo social, a aparência da mais completa "espontaneidade" e a realidade da mais total heteronomia possível. Relativamente a esse poder absoluto, todo poder explícito e toda dominação são deficientes, e dão testemunho de um fracasso irremediável. (Castoriadis, 1992: 126,127, grifos do autor.)

A heteronomia cria para o indivíduo inscrito na sociedade, submetido a tal estrutura de poder e, ao mesmo tempo, para o corpo social instituído, "a aparência da mais completa espontaneidade" ou, em outros termos, em uma sociedade heterônoma, o indivíduo e o coletivo social reduzem à níveis quase nulos sua capacidade de decidir, opinar, escolher, criticar, argumentar, ao fim e ao cabo, de criar. A autonomia sucumbe à introjeção da ordem de outrem, no indivíduo e na sociedade, assim, a ordem e a norma instituídas se reproduzem a partir da ordem e da norma introjetadas no indivíduo e se tornam autoinstituintes a partir da influência daquilo que Castoriadis vai denominar “infrapoder”, ou, no limite, da ação do "poder explícito”.

Antes de todo poder explícito, e muito mais, antes de toda “dominação”, a instituição da sociedade exerce um infrapoder radical sobre todos os indivíduos produzidos por ela. Esse infrapoder manifestação e dimensão do poder instituinte do imaginário radical - não é localizável. Certamente, nunca é o poder de um indivíduo ou mesmo de uma instância designáveis. É exercido pela sociedade instituída; todavia, atrás desta mantém-se a sociedade instituinte (...). [É] o poder do próprio campo social-histórico, o poder de outis, de Ninguém.” (Castoriadis, 1992: 127)

Apesar da presença desse poder instituinte, o infrapoder, o qual é constantemente exercido pela instituição da sociedade, este não é absoluto:

A sociedade instituída nunca consegue exercer o seu infrapoder de forma absoluta. No máximo - como é o caso das sociedades selvagens e, mais geralmente, das sociedades que devemos chamar de tradicionais - ela pode chegar a instaurar uma temporalidade da aparente repetição essencial, sob a qual trabalha, imperceptivelmente e por longos períodos, sua não-eliminável historicidade. Logo, enquanto absoluto e total, o infrapoder da sociedade instituída está condenado ao fracasso. (Castoriadis, 1992: 128)

Ou seja, ainda que o infrapoder trabalhe permanentemente sobre o imaginário social e sobre as instituições (indivíduo e sociedade), constituindo relações e espacialidades heterônomas, sempre haverá fissuras neste conjunto onde heterotopias (espaços outros) e heterocronias (temporalidades outras) podem vir a existir.

Sempre poderão ocorrer “linhas de fuga” (Deleuze e Guattari, 1995) que suscitem a produção de espaços e temporalidades a partir da auto- 
consciência, da reflexividade e do livre questionamento da ordem geral instituída. Ainda que, a partir de valores societais comuns, permeados de inferências que remetam à ordem introjetada, ao imaginário social instituído, seja possível a construção de valores, de outras formas de conduta capazes de fomentar uma espacialidade mais profícua ao projeto de autonomia. Uma espacialidade onde haja

a presença de instituições sociais que garantam a igualdade efetiva -e não apenas formal- de oportunidades aos indivíduos para a satisfação de suas necessidades e, muito especialmente, para participação em processos decisórios relevantes para a regulação da vida coletiva; em outras palavras, tem a ver com as instituições sociais que permitem a existência de indivíduos autônomos (livres) e de indivíduos educados para a liberdade, a sua própria e a dos outros. (Souza, 2006:70)

Se o imaginário radical é fruto da pluralidade indefinida das sociedades humanas, seja esta interna - de indivíduos e psiques - ou externa da coexistência sincrônica e do contato com outras sociedades - tal pluralidade será mais um fator que poderá servir como veículo de promoção dessas "fissuras", dessas "linhas de fuga" e, conseqüentemente, dessas heterotopias.

É justamente o fato da estrutura não ser o único determinante da ação e das conjunturas serem plurais e múltiplas, que vai possibilitar a existência dos questionamentos da ordem do sócios, as fissuras e, consequentemente, a materialização dessas formas "outras” de conduta a partir de uma "outra” espacialidade. Não necessariamente autônoma em plenitude, mas, conforme Souza (2006), com consideráveis "ganhos de autonomia” em relação àquelas que questionam.

Uma sociedade verdadeiramente democrática, no entender de Castoriadis, é uma sociedade que garante aos seus cidadãos, individual e coletivamente, não a "participação" política no sentido de partilhar de instituições políticas já definidas (instituídas), mas a participação na formulação, elaboração das normas que regem a instituição da sociedade e seus indivíduos. Só quando os cidadãos puderem partilhar verdadeiramente a formulação do nomos, isto é, das leis que os regem individual e coletivamente, é que se atingirá a democracia radical. Enquanto essa democracia radical não é alcançada, ações como as dos sem-teto, contribuem para a obtenção, como nos diz Souza (2006), de ganhos relativos de autonomia, aproveitando as fissuras, as imperfeições da instituição social heterônoma.

Todavia, para superar o fato de que essas fissuras existem, persistem e produzem frutos, haverá sempre o que Castoriadis vai chamar de "poder explícito", o poder cuja função essencial é "restabelecer a ordem, garantir a vida e a operação da sociedade contra todos e contra tudo o que atual ou potencialmente, a coloca em perigo” (Castoriadis, 1992:130). 
Lançando mão do mesmo exemplo que tem sido colocado nesse trabalho, a experiência do movimento dos sem-teto, ainda que as ocupações por eles promovidas (ou, pelo menos, algumas delas) tenham em seu germe um projeto mais radical de autonomia e autogestão e que busquem alternativas, processuais e simbólicas, ao imaginário capitalista e à democracia representativa como forma de organização política hegemonicamente utilizada, elas encontram-se inseridas, enquanto coletivo de sujeitos, bem como cada um dos seus integrantes individualmente, nesta mesma sociedade e nesta mesma organização política a qual criticam e à qual se opõem.

Seria assaz ingênuo pensar que essas ocupações, enquanto partes do “tecido sócio-espacial” urbano e, consequentemente, partes de toda uma rede de relações e significados construídos social e espacialmente, poderiam passar "impunemente", isto é, sem nenhuma interferência da espacialidade e suas relações de poder heterônomas. Não seria factível. Mas é importante frisar que o esforço e a resistência existem.

Tais espaços tentam ser a exceção cujo entorno - um espaço urbano altamente segregado, alienado, despolitizado, enfim, profundamente heterônomo - é a regra.

A luta nessas ocupações é, ao mesmo tempo, a luta que parte do movimento social urbano em sentido forte ${ }^{3}$ - contra a injustiça social, contra a avassaladora privatização do espaço urbano, contra a falta de emprego e moradia e contra a falta de participação (especialmente dos pobres) nas decisões políticas que dizem respeito á sua cidade, seu bairro, sua vida mas também é a luta que reside dentro do próprio movimento e dentro das próprias ocupações, no sentido de fazer germinar e alimentar uma verdadeira educação para a autonomia ${ }^{4}$.

Essa luta para promover mudanças que trabalhem no e o imaginário coletivo, isto é, para enfrentar um imaginário, um corpo sócio-histórico acostumado e acomodado à heteronomia, ao paternalismo, à tutela, é uma luta pela e através da paideia. É uma luta para se produzir e sustentar espaços que possam ser enxergados com olhos diferentes daqueles muitos que partem "de fora dos portões" para dentro. A transformação desse olhar de quem está dentro pode ser tão difícil (mas não impossível!) quanto a transformação do olhar de quem está de fora, pois, quem está na contraparte (na luta) é, quase sempre, tão íntimo daquela realidade à qual se contrapõe quanto se em tal posição não estivesse.

Entre os pensadores aqui mencionados, Castoriadis, Foucault, Guattari, Hannah Arendt, todos partidários de uma concepção libertária da política, a valorização do espaço como categoria de análise, ao menos explicitamente, não se mostrou fundamental na afirmação de um projeto de autonomia e o que figurou como a tônica de suas análises e suas obras, quando muito (como no caso de Foucault), foram as "formas espaciais que separam e protegem” (Souza, 2006:321). Porém, segundo Souza, "em se tratando de poder autônomo e da participação popular, interessam, 
sobretudo, as formas e os objetos geográficos que propiciam a reunião e o encontro". (Souza, 2006: 321)

Nesse sentido, é fundamental

a análise e a exploração das possibilidades de transformação e uso do espaço para fins de sua acomodação às necessidades de uma gestão da cidade a mais democrática possível, mesmo ainda no interior de uma ordem heterônoma. (Souza, 2006: 321)

Quando os sem-teto refletem sobre a situação da classe trabalhadora nas grandes metrópoles brasileira, decidem se colocar em movimento na contra-mão do projeto capitalístico de sociedade e, quando muito, assistencialista da democracia representativa em que vivemos e passam a agir de forma direta, colocando em prática projetos de ocupação e transformação de terrenos, edifícios e regiões da cidade, não estão fazendo nada mais do que "inaugurar um outro tipo de sociedade, com outro tipo de indivíduos”, que refletem, questionam(-se), decidem e põe em prática, contribuindo para a afirmação de outras espacialidades, de heterotopias (ainda espaços de poder, contudo) com ganhos de autonomia, em sociedades profundamente heterônomas.

\section{Considerações finais}

Diante do que foi exposto, o papel dos movimentos emancipadores modernos, como os movimentos sociais - movimento operário, feminista, movimentos étnico-raciais, ecológico, sem-teto, sem-terra etc. - será justamente de questionar a ordem instituinte e instituída, lutar por uma democracia radical e direta e por uma espacialidade justa, igualitária e que dê margem à autonomia (individual e coletiva), ou seja, a liberdade.

Pode haver democracia, ou pode haver, para todos que assim quiserem, igual possibilidade efetiva de participar do poder, numa sociedade onde existe e se reconstitui constantemente formidável desigualdade de poder econômico, imediatamente traduzível em poder político? Ou então, pode haver democracia, numa sociedade que, tendo concedido há algumas décadas os "direitos políticos” às mulheres, continua de fato a tratá-las como "cidadãos passivos”? As lei da propriedade (privada, ou "do Estado”) caíram do céu? (Castoriadis, 1992: 144,145, aspas do autor.)

Os movimentos sociais, como o caso dos sem-teto, vêm tentando ultrapassar as adversidades de um espaço heterônomo, ou seja, hostil, excludente e no qual a capacidade de decidir concedida aos indivíduos é constantemente reduzida. Este espaço social é reproduzido por um modelo de produção "flexível” e "desregulamentado" e, por isso, simplesmente incapaz de propiciar condições dignas de trabalho e sobrevivência para 
todos os cidadãos, incapaz de gerar e assegurar empregos, moradias adequadas, educação, saúde, não apenas como forma de transformação do modelo vigente, mas como justiça social e efetiva participação de todos nas decisões, afirmando a verdadeira política.

Os sem-teto, em sua proposta e práticas organizativas, segundo Souza (2006: 304,305), avançam na direção de uma regularização fundiária e direito à moradia que está para além dos marcos legalmente (juridicamente) instituídos no Brasil já que estes não propõem uma legalização e reintegração do solo à lógica (preexistente) do mercado, mas ao contrário, buscam a constituição de circuitos econômicos alternativos (solidários), ambientes culturais contestatórios (livres) e modos de vida autogestionários.

Este poderia ser um exemplo das possibilidades através das quais um indivíduo e uma sociedade, enquanto coletividade de indivíduos, podem ser autônomos, no sentido do que seja autonomia como aqui foi exposto. Tais práticas ajudam a entender ainda, e talvez conseguir avançar um pouco mais utilizando as contribuições de Castoriadis e Foucault, no sentido de se pensar a produção de um espaço urbano diferente. Esses autores têm nos ajudado a pensar na possibilidade de se criarem e reproduzirem heterotopias urbanas, como espaços onde a organização política, as decisões que dizem respeito ao coletivo e seus indivíduos, a rigor, as relações de poder, sejam diferentes das que conhecemos, sejam outras, sejam livres.

\section{Mas como avançar desse projeto de autonomia?}

Entendida a idéia de autonomia como aqui exposta, amparados por Castoriadis (1982, 1992, 2002, 2004), Souza (2006), como um projeto, um horizonte, devemos tomá-la então como uma alternativa possível ao capitalismo burocrático e à democracia representativa que reproduzem formas sempre mais verticalizantes de organização social e cada vez mais alienantes de participação política, onde a perspectiva de emancipação do indivíduo e da sociedade parece cada vez mais distante.

Souza (2006:112) nos lembra: a autonomia “plena”, deve nos servir como um "horizonte estratégico de pensamento e ação”, como um princípio e um norte que orienta os caminhos para ganhos reais de autonomia na criação de uma "sociedade basicamente autônoma", uma sociedade real e concreta que não está livre de injustiças e desigualdades, mas onde as instituições estejam permanentemente abertas às questões sociais e à busca constante de um desenvolvimento sócio-espacial como processo que conduza à uma mudança verdadeiramente emancipatória.

O espaço herdado da heteronomia, e não somente as relações sociais em si mesmas, constitui um obstáculo, um estorvo, a ser superado. O mesmo vale para todas as tentativas de obter ganhos de autonomia mesmo dentro de uma sociedade heterônoma: a criação de institucionalidades e rotinas que favoreçam a participação popular, uma maior justiça social e uma melhor qualidade de vida exige uma 
“espacialização” adequada, em matéria de malha territorial, de formas espaciais, de incorporação e valorização de sentimentos de lugar, de eliminação de signos opressores inscritos na paisagem... (Souza, 2006:112)

A idéia de democracia, para Castoriadis, esta está longe de ser um simples movimento de "igualização" da sociedade (Castoriadis, 2004:205). Ao contrário. A igualdade, em uma sociedade autônoma, que admite diferenças e oposições, significa autonomia estendida à todos, participação de todos na determinação e "execução" das leis, negociação das “diferenças", igual participação no poder, logo, exige liberdade.

É preciso multiplicar e ampliar essas possibilidades, esses horizontes de ação e de luta para que, desta forma, possamos também multiplicar a ampliar as possibilidades de criação de espaços autônomos, de heterotopias urbanas, como as que vêm sendo criadas pelos sem-teto através de suas ocupações.

Com freqüência, nas bordas do sistema podem ser observados sinais e evidências não só de reapropriação e ressignificação de espaços públicos [e também antigos espaços privados] (como bem mostram os grafites do hip-hop), como também de criativa conversão de espaços improváveis em palcos improvisados de algum tipo de cena pública, menos ou mais inclusiva, especialmente por parte de jovens. Isso “compensa” a negatividade das tendências observáveis? Decerto que não. São, essas ramificações, suficientes, por si sós, para reverter o quadro? Por enquanto não passam de reações interessantes, mas não muito mais do que isso. Mas são, também, sintomáticas no sentido de que a tese do "conformismo generalizado" não pode ser absolutizada a ponto de nos segar para o que se passa "nas nossas barbas”, e sintomas de que é justamente nas bordas do sistema e em meio aos escombros que ele produz que devem ser procurados os germes e os maiores potenciais da superação do quadro por todos lamentado. É da luta por autonomia e do apoio a iniciativas que representem ganhos de autonomia que, enfim, se trata... (Souza, 2006:329,330, grifos e aspas do autor.)

Aproveitar as "fissuras do sistema" e as "rugosidades do espaço herdado" é uma estratégia fundamental para se avançar na obtenção de ganhos de autonomia, seja através da luta cotidiana pela construção de uma consciência de direitos e deveres que somem ao coletivo da sociedade, seja através de uma "pedagogia urbana" que remonte à paideia e que contribua para a educação das mentes e dos espíritos para ambição da liberdade, seja através da criação de espaços outros, heterotopias autônomas, onde as relações de poder não sejam majoritariamente desproporcionais e opressoras, mas possam contribuir para a auto-reflexão, autodeterminação e autogestão. 


\section{Notas}

*Agradeço ao meu orientador, Prof. Dr. Marcelo Lopes de Souza, em cuja disciplina, oferecida no PPGG/UFRJ, esse artigo foi desenvolvido e avaliado. Aos demais amigos do NuPeD, Glauco Rodrigues, Eduardo Tomazine, Matheus Grandi, Marianna Moreira, Rafael Almeida e Amanda Lima, pelas discussões que alimentam as inquietações. Agradeço ainda ao amigo Prof. Dr. Carlos Walter Porto-Gonçalves pelas contribuições na finalização do artigo e por aquelas que oferece sempre.

${ }^{1}$ O texto “Outros Espaços” (Des Espace Autres, no original) escrito por Foucault em 1967, foi publicado pela primeira vez pelo periódico francês "Architecture-Mouvement-Continuité" em outubro de 1984. O texto não foi revisado pelo autor para publicação, também não foi incorporado por ele ao corpo oficial de seu trabalho, tendo sido trazido à publico apenas após a sua morte em 1984. O texto tem origem em notas de uma conferência proferida por Foucault e guarda, assim como outros trabalhos do mesmo autor, as características deste estilo de manuscrito.

${ }^{2}$ Sua "arqueologia do saber" - método próprio de análise da discursividade local - e sua "genealogia do poder" - tática que a partir da arqueologia ativa saberes libertos da sujeição - configuram um substancial avanço para a discussão acerca do poder, pois tratam-no sob uma nova ótica e a partir de uma diferente perspectiva, algo que, guardando a medida cronológica, já vinha sendo feito, por exemplo, por Hannah Arendt, pensadora que dedicouse a esse tipo de reflexão desde a década de 1950.

${ }^{3}$ Para a definição de "movimento social urbano em sentido forte”, vide SOUZA, 2006, cap.4.1.

${ }^{4}$ Na Grécia antiga, essa educação era a paideia, ou o processo de formação do caráter do indivíduo em sua forma verdadeira, natural e genuinamente humana. Consistia na educação que ia do nascimento à morte dos indivíduos, sendo, desta forma, "uma dimensão central de toda política da autonomia”. 


\section{Bibliografia}

Arendt, Hannah (2003), A Condição Humana. Ed. Forense. Rio de Janeiro.

Ídem (2004), Da violência. http://www.sabotagem.revolt.org.

Almeida, Rafael; Grandi, Matheus e Moreira, Marianna (2009), “Óikos, Ágora e Ekklesia: Uma introdução às fronteiras, pontes e “áreas de sombra” de um espaço ocupado por sem-teto (Ocupação Quilombo das Guerreiras - Rio de Janeiro)”. Em Revista Cidades, v.6, n.9, Presidente Prudente.

Castoriadis, Cornelius (1982), A instituição imaginária da sociedade. “A instituição e o imaginário: primeira abordagem”. Ed. Paz e Terra. Rio de Janeiro.

Ídem (1992), As encruzilhadas do labirinto III. O mundo fragmentado. “Poder, Política, Autonomia”. Ed. Paz e Terra. São Paulo.

Ídem (2002), As encruzilhadas do labirinto IV. A ascensão da insignificância. "A democracia como procedimento e como regime”. Ed. Paz e Terra. São Paulo.

Ídem (2004), As encruzilhadas do labirinto VI. Figuras do Pensável. "Que democracia?”. Ed. Civilização Brasileira. Rio de Janeiro.

De Certau (1996), Michel. A invenção do Cotidiano. Artes de fazer. “Caminhadas pela cidade”. Ed. Vozes. Petrópolis.

Deleuze, Gilles e Guattari, Félix. Mil Platôs. Vol. 3. Editora 34, Rio de Janeiro.

Foucault, Michel (1986), “Of other spaces”. Diacrities, v.16, no.1.Baltimore.

Ídem (2001), “Outros Espaços”. In: Motta, Manoel Barros da (org.): Michel Foucault: Estética: Literatura e pintura, música e cinema. Ed. Forense Universitária. Rio de Janeiro e São Paulo.

Ídem (1998), Microfísica do poder. Ed. Graal. Rio de Janeiro.

Ídem (1998a), Vigiar e Punir. História da violência nas prisões. Ed. Vozes. Petrópolis.

Santos, Milton (2002), Por uma Geografia nova. Ed. Hucitec. São Paulo.

Ídem (1979), O espaço dividido: os dois circuitos da economia urbana dos países subdesenvolvidos. Ed. Francisco Alves. Rio de Janeiro. 
Souza, Marcelo Lopes (1998), O que pode o ativismo de bairro? Reflexão sobre as limitações e potencialidades do ativismo de bairro à luz de um pensamento autonomista. Dissertação de Mestrado em Geografia. Programa de Pós-Graduação em Geografia da Universidade Federal do Rio de Janeiro, 1988.

Ídem (2006), A prisão e a ágora: Reflexões em torno da democratização do planejamento e da gestão das cidades. Ed. Bertrand Brasil. Rio de Janeiro.

Ídem (2008), “Ativismos sociais e espaço urbano: Um panorama conciso da produção intelectual brasileira”. Em Oliveira, M. Piñon; Coelho, Maria Célia N. e Corrêa Aureanice M. O Brasil, a América Latina e o mundo: Espacialidades contemporâneas II. Ed. Lamparina, FAPERJ, ANPEGE. Rio de Janeiro.

Recibido: 12.08.2009

Aceptado: 15.06.2010 